\title{
Composição físico-química de amostras de pólen coletado por abelhas Africanizadas Apis mellifera (Hymenoptera:Apidae) em Piracicaba, Estado de São Paulo
}

\author{
Physico-chemical composition of pollen samples collected by Africanized Apis mellifera \\ (Hymenoptera:Apidae) in Piracicaba, State of São Paulo, Brazil
}

\author{
Luís Carlos Marchini $^{1}$ Vanderlei Doniseti Acassio dos Reis ${ }^{2}$ \\ Augusta Carolina de Camargo Carmello Moreti $^{3}$
}

\section{RESUMO}

Com o objetivo de se verificar a composição físicoquímica de amostras do pólen coletado por abelhas Africanizadas, foram realizadas coletas em cinco colméias de abelhas Apis mellifera Africanizadas utilizando coletores de pólen de alvado (frontais) com orifícios de 4,00mm de diâmetro, em Piracicaba, São Paulo, durante um ano (março de 1999 a março de 2000). A composição química das amostras foi determinada no Laboratório de Apicultura do Departamento de Entomologia, Fitopatologia e Zoologia Agrícola, ESALQ/ USP. Foram obtidas as seguintes médias: $21,5 \%$ de proteínas; $2,8 \%$ de cinzas; $23,6 \%$ de umidade; $76,3 \%$ de resíduo seco; 3,5\% de lipídios; 28,4\% de açúcares totais; 20,7 mEq $\mathrm{kg}^{-1}$ de pólen de acidez titulável e pH igual a 5,1. Para análise estatística, foram considerados todos os dados referentes aos diferentes dias de coleta, sendo as médias mensais comparadas pelo teste de Tukey em nível de 5\%. Foram verificadas diferenças significativas nas médias ao longo do ano para os diferentes parâmetros estudados, com exceção da porcentagem de cinzas que não apresentou variação significativa.

Palavras-chave: Apis mellifera, composição físico-química, pólen.

\section{ABSTRACT}

Pollen samples were collected from March, 1999 to March, 2000, in Piracicaba, State of São Paulo, Brazil, from 5 beehives of Africanized Apis mellifera by using front pollen collectors with openings $4 \mathrm{~mm}$ diameter. The aim of this study was to determine the physico-chemical composition of pollen. Chemical composition of samples was determined at the Laboratório de Apicultura of the Escola Superior de Agricultura “Luiz de Queiróz”, Universidade de São Paulo. The following mean values were obtained: $21.5 \%$ proteins; $2.8 \%$ ashes; $23.6 \%$ moisture; $76.3 \%$ of dry residue; $3.5 \%$ lipids; $28.4 \%$ of total sugars; $20.7 \mathrm{mEq} \mathrm{kg}^{-1}$ of pollen of titrate acidity and $\mathrm{pH}$ 5.1. The statistical analyses considered all data concerning the different days and comparison of the monthly means were made by Tukey's test $(P<0.05)$. There were significant differences along the year, to the different parameters studied, except for ashes which percentage did not present significant variation.

Key words: Apis mellifera, physico-chemical composition, pollen.

\section{INTRODUÇÃo}

A importância do pólen para a colônia é inquestionável, pois dele dependem as abelhas para o seu suprimento de proteínas, sais minerais e produtos biológicos especiais utilizados na sua alimentação. Por essa razão, a produção de mel, cera e geléia real de um apiário está diretamente relacionada com a quantidade de pólen necessária para a alimentação das colmeias.

As abelhas, na ausência de pólen, recorrem à sua própria fonte de reserva, metabolizando tecidos de seus corpos para prolongar sua existência. Ao receberem material nutritivo, no caso pólen, rapidamente assimilam os principais nutrientes que

\footnotetext{
${ }^{1}$ Departamento de Entomologia, Fitopatologia e Zoologia Agrícola, Escola Superior de Agricultura "Luiz de Queiroz”, Universidade de São Paulo (ESALQ/USP), Av. Pádua Dias, 11, 13418-900, Piracicaba, SP, Brasil. E-mail: lcmarchi@carpa.ciagri.usp.br. Autor para correspondência

${ }^{2}$ Embrapa Pantanal, Centro de Pesquisa Agropecuária do Pantanal, Rua 21 de Setembro, 1880, 79320-900, Corumbá, MS, Brasil. E-mail: reis@cpap.embrapa.br.

${ }^{3}$ Centro de Pesquisa e Desenvolvimento de Zootecnia Diversificada, Instituto de Zootecnia, Agência Paulista de Tecnologia dos Agronegócios, Secretaria de Agricultura e Abastecimento, 13460-000, Nova Odessa, SP, Brasil. E-mail: acmoreti@izsp.br.
} 
haviam perdido, reintegrando-se à normalidade (HAYDAK,1934)

As abelhas necessitam de 10 aminoácidos essenciais: arginina, histidina, lisina, triptofano, felinanima, metionina, treonina, leucina, isoleucina e vanila, os quais são todos obtidos do pólen. Uma dieta deficiente em qualquer um destes aminoácidos pode gerar sintomas específicos de deficiência, uma vez que as abelhas não poderão sintetizar as proteínas que os contenham (HAYDAK, 1970).

Experimentos de alimentação demonstram uma necessidade média de $145 \mathrm{mg}$ de pólen para que uma abelha operária complete seu ciclo de vida. Assim, 10.000 operárias (que formam uma pequena colônia) consomem 1,5kg de pólen. O valor nutritivo do pólen armazenado artificialmente depende das condições de secagem, temperatura e duração do tempo de armazenamento e da planta de origem do pólen. Todos esses fatores indicam que a composição química é a chave que determina a utilidade do pólen na nutrição da abelha (STANLEY \& LINSKENS, 1974).

A composição do pólen varia entre espécies de plantas; também sofre a influência da idade, da condição nutricional da planta e das condições ambientais durante o desenvolvimento do pólen (HERBERT Jr. \& SHIMANUKI, 1978).

Além da nutrição das abelhas, o pólen coletado no alvado das colmeias pode ser utilizado como complemento alimentar na nutrição humana, pois é uma importante fonte de proteínas. Assim o conhecimento de sua composição física e química, torna-se importante, no sentido de tipificar o produto obtido em diferentes regiões.

O pólen para ser comercializado no Brasil deve ter os seguintes requisitos físico-químicos: umidade máxima de 30\%; cinzas máximo de $4 \%$; lipídeos, mínimo de 1,8\%; proteínas, mínimo de 8\%; açúcares totais de $14,5 \%$ a 55,0\%; fibra bruta, mínimo de $2 \%$ e pH de 4 a 6 (BRASIL, 2001).

A composição química de diversas plantas (trevo branco, salgueiro, Pinus sp., Rubus sp., kiwi, etc) utilizadas por $\boldsymbol{A}$. mellifera para a coleta de pólen na Nova Zelândia foi determinada por DAY et al. (1990), verificando que a umidade variou de $16,8 \%$ a $25,9 \%$; lipídeos, de 0,17\% e 13,40\%; carboidratos, de 12,6 a 28,6\%; o teor de açúcares redutores, de 11,1 a 25,7\% e proteínas, de 2,9 a 23,5\%. Concluíram que a maioria das plantas analisadas contém nutrientes suficientes para o crescimento e desenvolvimento da abelha melífera.

O pólen coletado por $\boldsymbol{A}$. mellifera no Brasil (Paraná) teve umidade variando de 2,61\% a 11,06\%; proteínas, de 13,84\% a 27,84\%; lipídeos, de 2,17\% a 5,63\%; cinzas, de 1,58\% a 3,61\%; açúcares redutores, de 19,40\% a 28,25\%; açúcares não redutores, de 1,07\% a 5,55\%; fibra bruta, de $1,58 \%$ a 3,61\% e pH, de 4,60 a 5,90 (SAMPAIO,1991).

Em determinação bromatológica e mineral do pólen coletado por A. mellifera no Brasil (Botucatu), no período de agosto a novembro de 1996, FUNARI et al. (2003) encontraram os seguintes valores: 75,9\% de matéria seca, 26,2\% de proteína bruta, 5,1\% de lipídeos, $1,1 \%$ de fibra bruta e 2,6\% de minerais com os seguintes valores: 0,4\% de P; 0,67 de K; 0,26\% de Ca; 0,08 de Mg; $0,21 \%$ de $S ; 114 \mathrm{mg} \mathrm{kg}^{-1}$ de Fe; $88 \mathrm{mg} \mathrm{kg}^{-1}$ de Zn; $15 \mathrm{mg}$ $\mathrm{kg}^{-1}$ de Cu; $32 \mathrm{mg} \mathrm{kg}^{-1}$ de Mn e $10 \mathrm{mg} \mathrm{kg}^{-1}$ de Bo.

O teor de lipídeos presente no pólen de espécies de plantas utilizadas por A. mellifera para a coleta na Índia foi de 20,3\% para Brassica campestris var. toria, 19,4\% para Cosmos bipinnatus, 17,8\% para Raphanus sativum, 11,9\% para Helianthus annuus e 11,6\% para Petunia hybrida (SINGH et al.,1999).

O principal objetivo do presente trabalho foi a determinação da composição físico-química das amostras de pólen produzidas ao longo do ano na região de Piracicaba, SP, com a finalidade de serem utilizados os dados obtidos em futuros estudos de nutrição de abelhas, bem como fornecer resultados para que possa ser tipificado este produto apícola. Os valores obtidos foram comparados com as exigências da legislação brasileira, com o intuito de verificar se o pólen produzido enquadra-se nas normas vigentes.

\section{MATERIAL E MÉTODOS}

A coleta de pólen para as análises físicoquímicas foi realizada por meio de coletores de alvado, com orifícios de 4,00mm de diâmetro, em cinco colmeias, durante o período de março de 1999 a março de 2000. Depois de limpado manualmente e secado em estufa, de acordo com a metodologia proposta por FUNARI et al. (2003), foi acondicionado em recipientes de plástico de $200 \mathrm{~mL}$, hermeticamente fechados e armazenados sob refrigeração (cerca de $7^{\circ} \mathrm{C}$ ) até a sua utilização nas análises físico-químicas.

Para as determinações de porcentagens de Nitrogênio protéico (digestão ácida), cinzas (resíduo por incineração), umidade (perda por dissecação), resíduo seco (sólidos totais), lipídeos (extração com solventes), pH (determinação eletrométrica) e acidez titulável (titulação), foram usadas as metodologias constantes nas Normas Analíticas do Instituto Adolfo Lutz (INSTITUTO ADOLFO LUTZ, 1985). Para as porcentagens de açúcares redutores totais, foi adotada a metodologia proposta por MOKRASCH (1954).

O delineamento experimental utilizado foi o inteiramente casualizado. As médias mensais foram 
comparadas pelo teste de Tukey $(\mathrm{P}=0,05)$, através do programa SAS (1997).

\section{RESULTADOS E DISCUSSÃO}

Os dados referentes às porcentagens de proteína, cinzas, umidade, resíduo seco, lipídeos, açúcares totais e pH e acidez titulável, encontram-se na tabela 1.

As porcentagens de proteína em amostras de pólen coletadas por Apis mellifera apresentaram variações estatisticamente significativas, com máximo de 22,8 e mínimo de 20,1\% para os meses de julho e abril de 1999, respectivamente. O valor médio do teor de proteínas (21,58\%) encontrado no presente trabalho é muito próximo aos verificados por BARRETO et al. (2000) em Taubaté, SP, nos meses de maio e junho, que são de 20,3 e 20,0, respectivamente, e aos $20 \%$ de ALMEIDA-MURADIAN et al. (2004) para pólen produzido na região sul do Brasil, mas é inferior aos 30,4\% citado por COSTA et al. (2000), na região de Maringá, PR, e superior ao observado por PALMA (1992), que obteve 15,8 a 16,7\%.

As porcentagens de cinzas em amostras do pólen coletado por $\boldsymbol{A}$. mellifera não apresentaram variações estatisticamente significativas, com máximo de 3,1 e mínimo de 2,6\% para os meses de março de 2000 e agosto de 1999, respectivamente. Os resultados apresentaram pequena variabilidade nas médias durante os meses do ano. Os valores observados encontram-se na faixa de variação verificada por SAMPAIO (1991) (1,6 a 3,6\%) para pólen coletado no estado do Paraná, sendo o valor médio (2,87\%) pouco superior aos 2,2\% observados por ALMEIDAMURADIAN et al. (2004) para pólen produzido na região sul do Brasil.

As porcentagens de umidade em amostras do pólen recém coletadas por $\boldsymbol{A}$. mellifera apresentaram variações estatisticamente significativas, com máxima de 33,2 e mínima de 16,8\%, para os meses de janeiro e fevereiro de 2000, respectivamente. A alta umidade durante o mês de janeiro é explicada por ser este o mês mais chuvoso na região em estudo. Os resultados apresentaram grande variabilidade nas médias durante os meses do ano. Este fato pode ser explicado por ser o pólen um material altamente higroscópico, sendo, portanto, grandemente afetado pelas condições ambientais. Comparando com o trabalho de DAY et al. (1990), na Nova Zelândia, o limite interior observado por aqueles autores $(16,8 \%)$ é igual ao limite menor observado no presente trabalho, embora o limite superior de umidade $(25,9 \%)$ tenha sido bem menor que aos 33,18\% verificado durante o mês de janeiro na região de Piracicaba, SP.

As porcentagens de resíduo seco em amostras do pólen coletado por A. mellifera são inversamente proporcionais à umidade observada. A média $(76,3 \%)$ é próxima aos $75,9 \%$ obtidos por

Tabela 1 - Valores médios de proteína, cinzas, umidade, resíduo seco, lipídeos, pH, acidez titulável e açúcares totais em amostras de pólen de Apis mellifera obtidas em coletores de pólen de alvado (frontais), ao longo de um ano, em Piracicaba, SP.

\begin{tabular}{|c|c|c|c|c|c|c|c|c|c|}
\hline Ano & Mês & $\begin{array}{c}\text { Proteína } \\
\text { (\%) }\end{array}$ & $\begin{array}{c}\text { Cinzas } \\
\text { (\%) }\end{array}$ & $\begin{array}{l}\text { Umidade } \\
\text { (\%) }\end{array}$ & $\begin{array}{c}\text { Resíduo seco } \\
\text { (\%) }\end{array}$ & $\begin{array}{c}\text { Lipídeos } \\
\text { (\%) }\end{array}$ & $\mathrm{pH}$ & $\begin{array}{c}\text { Acidez } \\
\text { titulável (mEq } \\
\left.\mathrm{kg}^{-1}\right)\end{array}$ & $\begin{array}{c}\text { Açúcares } \\
\text { totais (AT) } \\
\text { (\%) }\end{array}$ \\
\hline \multirow{10}{*}{1999} & Março & $20,2 b *$ & $2,8 a$ & $25,8 a b c$ & $74,2 \mathrm{bc}$ & $2,4 \mathrm{fg}$ & 4,9ab & $19,5 \mathrm{c}$ & 31,1abc \\
\hline & Abril & $20,1 b$ & $2,8 a$ & $23,0 \mathrm{bc}$ & 77,0abc & $2,2 \mathrm{~g}$ & $5,2 \mathrm{ab}$ & $22,5 a$ & 27,5abcd \\
\hline & Maio & 21,5ab & $2,8 a$ & $22,9 b c$ & 77,0abc & 3,2defg & 5,2ab & 21,9abc & 31,0abcd \\
\hline & Junho & 20,6ab & $2,9 a$ & $21,7 \mathrm{bc}$ & 78,4abc & 2,9defg & 5,3a & 21,3abc & 36,0abcd \\
\hline & Julho & $22,8 a$ & $2,8 a$ & $21,6 b c$ & 78,5abc & 3,9bcde & 5,3a & 22,3ab & 21,7d \\
\hline & Agosto & $22,0 \mathrm{ab}$ & $2,6 a$ & $22,1 b c$ & 77,9abc & 4,8ab & $5,0 a b$ & 21,8abc & 25,2cd \\
\hline & Setembro & $22,1 \mathrm{ab}$ & $3,1 \mathrm{a}$ & $24,5 b c$ & $75,5 \mathrm{bc}$ & 4,3abc & 5,1ab & $20,2 a b c$ & 27,6abcd \\
\hline & Outubro & 21,3ab & $3,0 a$ & $19,0 \mathrm{c}$ & $81,0 a b$ & 3,4cdef & $5,0 a b$ & $20,7 a b c$ & $25,5 b c d$ \\
\hline & Novembro & $21,5 a b$ & $3,0 \mathrm{a}$ & $28,0 \mathrm{ab}$ & $72,0 \mathrm{~cd}$ & $5,1 \mathrm{a}$ & $5,0 a b$ & $19,9 b c$ & 26,5abcd \\
\hline & Dezembro & $21,5 a b$ & $2,8 a$ & $25,5 a b c$ & $74,5 b c$ & 2,9efg & $4,8 \mathrm{~b}$ & 21,3abc & 28,3abcd \\
\hline \multirow{3}{*}{2000} & Janeiro & $22,2 \mathrm{ab}$ & $2,8 a$ & $33,2 \mathrm{a}$ & $66,8 d$ & 4,0bcd & $5,2 a b$ & $20,7 a b c$ & 33,5ab \\
\hline & Fevereiro & $21,8 a b$ & $2,8 a$ & $16,8 \mathrm{c}$ & $83,2 a$ & 3,5cde & $5,0 a b$ & $20,6 a b c$ & $33,4 a b$ \\
\hline & Março & $20,2 b$ & $3,1 a$ & $23,1 b c$ & 76,9abc & 3,6cde & $5,0 \mathrm{ab}$ & $19,8 \mathrm{bc}$ & 33,9a \\
\hline Média & & 21,4 & 2,9 & 23,6 & 76,3 & 3,6 & 5,1 & 20,7 & 28,4 \\
\hline CV\% & & 4,9 & 8,9 & 16,8 & 4,7 & 13,4 & 4,3 & 5,6 & 13,2 \\
\hline
\end{tabular}

*Médias seguidas de letras distintas, nas colunas, diferem estatisticamente entre si em nível de 5\% de significância pelo teste de Tukey. CV= Coeficiente de Variação. 
FUNARI e al. (2003) em Botucatu, SP, e aos 72,5\% de COSTA et al. (2000), em Maringá, PR.

As porcentagens de lipídeos em amostras do pólen coletado por A. mellifera apresentaram variações estatisticamente significativas, com máximo de 5,1 e mínimo de 2,2\%, para os meses de novembro e abril de 1999, respectivamente. Os resultados apresentaram grande variabilidade nas médias durante os meses do ano, fato que pode ser explicado pelas variações que ocorrem nas composições das plantas de origem do pólen e também pelas necessidades diferenciadas das abelhas em determinados componentes presentes nos materiais coletados. Estes valores são próximos aos observados por SAMPAIO (1991) (2,2 a 5,6\%) para o pólen produzido no estado do Paraná e por PALMA (1992) (2,9 a 4,0\%), e um pouco inferiores aos $6 \%$ obtidos por ALMEIDA-MURADIAN et al. (2004) para pólen da região sul do Brasil.

As determinações eletrométricas do $\mathrm{pH}$ em amostras do pólen coletado por A. mellifera apresentaram variações estatisticamente significativas, com máxima de 5,3 e mínima de 4,8 para os meses de junho e dezembro de 1999, respectivamente. Os resultados apresentaram grande variabilidade nas médias durante os meses do ano; no entanto, em todas as análises realizadas, foram obtidos valores inferiores a 7, indicando que o material analisado é ácido. Poucos autores divulgaram os resultados obtidos para os valores de $\mathrm{pH}$ do pólen, como HERBERT Jr. \& SHIMANUKI (1978), que, em trabalho realizado nos Estados Unidos, obtiveram média de 4,8, e SAMPAIO (1991), que, no estado do Paraná, Brasil, observou valores de 4,6 a 5,9, todos próximos aos obtidos no presente trabalho.

A acidez titulável em amostras do pólen coletado por A. mellifera apresentaram variações estatisticamente significativas, com máxima de 22,5 e mínima de 19,5, para os meses de abril e março de 1999, respectivamente, tendo como explicação a grande variabilidade de origem botânica do pólen coletado.

As porcentagens de açúcares totais em amostras do pólen coletado por A. mellifera apresentaram variações estatisticamente significativas, com máxima de 33,9 e mínima de 21,7\%, para os meses de julho de 1999 e março de 2000, respectivamente. A variação observada tem como justificativa as variações que ocorrem nas composições das plantas de origem do pólen coletado. Comparando com os dados de literatura, verifica-se que HERBERT Jr. \& SHIMANUKI (1978) encontraram valores médios de $20,7 \%$, nos Estados Unidos, DAY et al. (1990), valores de 11,1 a 25,7\%, na Nova Zelândia, e SAMPAIO (1991) obteve valores na faixa de 19,4 a $28,2 \%$, no Brasil. Os menores valores observados foram pouco inferiores aos verificados no presente trabalho.

Comparando-se os valores obtidos para proteínas, cinzas, umidade, lipídios, $\mathrm{pH}$ e açúcares totais com as exigências estabelecidas pela legislação brasileira (BRASIL, 2001), verifica-se que todas as amostras coletadas ao longo do ano atenderam às exigências estabelecidas.

As abelhas são insetos sociais e, como tais, sua atividade e seu comportamento dependem do número de indivíduos que compõe a família. Uma colmeia mais populosa proporcionará maior coleta de alimento (SZABO, 1982), um número maior de nutrizes (MORAES \& CRUZ-LANDIM, 1984) e um melhor aquecimento (SEELEY, 1985).

A nutrição da colônia, principalmente em relação ao pólen, também influencia diretamente o desenvolvimento larval, já que a produção de crias está diretamente relacionada à quantidade de pólen coletada (SZABO, 1982; COUTO \& COUTO, 1988). FREE (1967); TOOD \& REED (1970) e COUTO et al.(1989) também encontraram relação direta entre a área de pólen e a de cria. Já COUTO et al. (1989) observaram relação positiva entre a área de pólen e mel.

Considerando que o pólen é matéria-prima para produção de geléia real, seria interessante a suplementação das colônias com uma fonte protéica nas épocas de escassez ou quando o pólen natural tem baixas porcentagens de proteínas (GARCIA et al., 1989).

\section{AGRADECIMENTO}

Os autores agradecem à FAPESP (Fundação de Amparo à Pesquisa do Estado de São Paulo), pelo financiamento do projeto no. 1998/05017-7, o que possibilitou a realização do presente trabalho.

\section{REFERÊNCIAS}

ALMEIDA-MURADIAN, L.B. et al. Chemical composition and botanical evaluation of dried bee pollen pellets. Journal of Food Composition and Analysis. (in press). Acesso em 01/09/2004. On Line. Disponível na internet em: www.elsevier.com/locate/jfca.

BARRETO, L.M.R.C. et al. Perfil protéico do pólen coletado por Apis mellifera (Híbrida africanizada) no período outonoinverno no apiário do Centro de Estudos Apícolas da Universidade de Taubaté. In: CONGRESSO BRASILEIRO DE APICULTURA, 13, 2000, Florianópolis. Anais... Florianópolis: CBA, 2000. (Compact disc).

BRASIL. Instrução Normativa n. 3 de 2001. Regulamentos técnicos de identidade e qualidade de apitoxina, de cera de abelha, de geléia real liofilizada, de pólen apícola, de própolis e de extrato de própolis. Acesso em 12/03/2004. On line. Disponível na internet em: http:// www.agricultura.gov.br/das/dipoa. 
COSTA, F.M. et al. Características produtivas e reprodutivas de colônias de Apis mellifera submetidas a alimentação natural na região de Maringá-PR. In: CONGRESSO BRASILEIRO DE APiCUlturA, 13, 2000, Florianópolis. Anais... Florianópolis: CBA, 2000. (Compact disc).

COUTO, L.A.; COUTO, R.H.N. Estudo do fornecimento de ração protéica em colmeias de Apis mellifera infestadas com Varroa jacobsoni. Revista Agropecuária Brasileira, v.23, n.2, p.119-122, 1988.

COUTO, R.H.N. et al. Produção de cria e alimento em colmeias de Apis mellifera confinadas e tratadas com ração protéica. Ecossistema, v.14, p.213-218, 1989.

DAY, S. et al. The nutrient composition of honey bee-collected pollen in Otago, New Zealand. Journal of Apicultural Research, v.29, n.3, p.138-146, 1990.

FREE, J.B. Factors determining the collection of pollen by honey bee foragers. Animal Beehaviour, v.15, p.134-144, 1967.

FUNARI, S.R.C. et al. Composições bromatológica e mineral do pólen coletado por abelhas africanizadas (Apis mellifera L.) em Botucatu, Estado de São Paulo, Brasil. Archivos Latinoamericanos de Producción Animal, v.11, n.2, p.8893, 2003.

GARCIA, R.C. et al. Efeitos do fornecimento de farelo de trigo sobre o desenvolvimento da glândula hipofaringeana $e$ produção de geléia real em colmeias de Apis mellifera. Ciência Zootécnica, v.4, n.1, p.6-8, 1989.

HAYDAK, M.K. Changes in total nitrogen content during the life of the imago of to worker honey-bee. Journal of Agricultural Research, v.49, n.1, p.21-27, 1934.

HAYDAK, M.H. Honey bee nutrition. Annual Review of Entomology, v.15, p.143-153, 1970.

HERBERT JR., E.W.; SHIMANUKI, H. Chemical composition and nutritive value of bee-collected and bee-stored pollen. Apidology, v.9, n.1, p.33-40, 1978.

INSTITUTO ADOLFO LUTZ. Normas analíticas do Instituto Adolfo Lutz: métodos químicos e físicos para análise de alimentos. 3.ed. São Paulo: Instituto Adolfo Lutz, 1985. 533p.

MOKRASCH, L.C. Analysis of hexose phosphates and sugar mixtures with the anthrone reagent. Journal of Biological Chemistry, v.208, n.1, p.55-59, 1954.

MORAES, R.L.M.S.; CRUZ-LANDIM, C. Influência da densidade populacional no comportamento dos núcleos das glândulas hipofaringeanas de Apis mellifera (Hymenoptera, Apidae). Naturalia, n.9, p.27-33, 1984

PALMA, M.S. Composition of freshly harvested brazilian royal jelly: identification of carbohydrates from the sugar fraction. Journal of Apicultural Research, v.31, n.1, p.42-44, 1992.

SAMPAIO, E.A.B. Caracterização do pólen apícola processado comercial e armazenado na colmeia- pão de abelhas, de algumas localidades do Paraná. 1991. $118 \mathrm{f}$. Dissertação (Mestrado em Entomologia) - Universidade Federal do Paraná.

SAS INSTITUTE. SAS/STAT software: changes and enhancements through release 6.12. Cary, 1997. Acesso em 24 de maio de 2005. On line. Disponível em: http:// www.cpc.unc.edu.

SEELEY, T.D. Honey bee ecology. A study of adaptation in social life. Princeton: Princeton University, 1985. 201p.

SINGH, S. et al. Quantitative comparison of lipids in some pollens and their phagostimulatory effects in honey bees. Journal of Apicultural Research, v.38, n.1-2, p.87-92, 1999.

STANLEY, R.; LINSKENS, H. Pollen: biology, biochemistry and management. Heidelberg: Springer-Verlag, 1974. 307p.

SZABO, T.I. Phenotypic correlations between colony traits in honey bee. American Bee Journal, v.122, n.10, p.711-716, 1982.

TOOD, F.E.; REED, C.B. Brood measurement as a valid index to the value of honey bees as pollinators. Journal of Ecological Entomology, v.63, n.1, p.148-149, 1970. 